\title{
CARTÕES DE CRÉDITO NO SETOR DE TURISMO
}

\author{
Antônio de Carvalho Brigagão1
}

\begin{abstract}
RESLM( ): Relata o início e a evolução dos cartōes de crédito. descre. vendo alguns dados do seu crescimento no mercado norte-americano. Destaca o segmento turístico dos cartōes de crédito. atualmente em expansão, analisando: vantag(ns e comodidades tanto para as cmpresas e fornecedores. quanto para us próprios turistas: atuação da (.redicard S.A.. em termos de ações pringramadas para ampliar o scu espaço no segmento turístico.
\end{abstract}

PAL.AVRAS-CHAVE: Turismo: cartōes de crédito: cmpresas. Cartōes de crédito: cmpresas: marketing.

ABSTRAC T: Describes the beginning and the cololution of credit cards, giving some data of it 's grouth in the North American market. Puts in relicf the touristic segnent of credit cards, now in cxpansion, analizing: adiantages and easness for enterprises and supplicrs, as for tourists; Credicard's SA perfommance in tenns of programmed actions to increase it sspace in the touristic segne'tu.

KEY WORDS: Tourism: credir cards; cnterprises. (redit cards: crnterprises, markcting.

\section{INTRODU(CÃ)}

Quando Alfred Bloomingdalc, Frank McNamara c Ralph Snyder se sentaram para almoçar no Major's Cabin (irill, um restaurante famoso da cidade de Nova Iorque eın 1949, para conversar sobre planos e problemas de trabalho, nāo podleriam imaginar que daquele "papo" despretensioso entre amigos estava nascendo um dos maiores negócios deste

1 Bacharel em F conomia pela Universidade Mackenzic. (urso de İxtcnsão Universıtária em Finanças e Marketing pela Funclação Getúlio Vargas. Presidente da ('REDIC,ARD S.A.

End. para corresp.: Credicard S. A. - Av. Brig. Faria Lima. $2161-10^{\circ}$ andar - $01451-914$ - São Paulo - SP - Brasil. 
século: a internacional e multibilionária indústria dos cartóes de crédito Da troca excitada de idéias entre o vendedor McNamara, o produtor de espetáculos Bloomingdale e o advogado Snyder surgiu o Diners Club, cartāo pioneiro de um setor que, passados mais de quarenta anos, transformou a maneira como negociantes e consumidores conduzem suas vidas.

Em todo o mundo, mas especialmente nos Estados Unidos - terra natal do cartāo de crédito -, o número de pessoas que o possui e o utiliza é espantoso. Já por volta de 1984, 71\% das famílias norte-americinas possuíam ao menos um cartāo. $\mathrm{O}$ segmento dos cartōes de crédito bancários foi dos que experimentou maior expansāo: de 1970 a 1986, o número de familias possuidoras destes cartōes saltou de $16 \%$ para $55 \%$. enquanto 34\% dispōem de cartōes de combustível (MANDELL, 19')0).

$\mathrm{Na}$ mesma época, o cartāo mais popular era o Visa, utilizado por 45,3\% de americanos com idades entre 17 e 65 anos, seguido pelo Sears $(38,4 \%)$ e MasterCard (30,1\%). O campeāo no segmento dos cartōes de combustível era o Amoco, com $13,9 \%$ deste universo, seguido pelo da Sheel, com 9,5\%. () American Express atingia 12,5\% da populaçāo norte-americana, seguido pelo Discover, que era utilizado por $9,5 \%$ dos consumidores do mercado norte-americano (MANDELL, 1990).

Desde que foram criados os cheques de viagem, no final do século passado, a preocupaçāo quantı) à segurança e conveniência nas transaçōes entre pessoas e instituiçō's inspirou um sem número de iniciativas empresariais nesse sentido: a criaçāo de carnês c cartōes de compras por grandes lojas de departamentos: experiências bancárias com cartōes para clientes; cartōes para compras, restaurantes e viagens no Brasil e exterior. Já em meados de 1950, havia nos Estados Unidos mais de uma centena de cartōes de crédito à disposiçāo do público consumidor. Era o prenúncio do que ficou conhecido como a era do "comércio de plástico".

As facilidades proporcionadas aos usuários de cartōes de crédito sāo imensas e inerentes aos tempos modernos. Em muitos países, onde 0 uso desse meio de pagamento $e$ : largamente difundido, o usuário pode:

a) reservar passagens aéreas e recebê-las em casa com apenas um telefonema;

b) garantir reservas em hotćis c restaurantes;

c) alugar veículos;

d) sacar dinheiro em caixas expressas e até em hotéis.

\section{CARTÃO DE CREDITO E TURISMO}

Um dos segmentos do cartāo de crédito em expansão é o) turístico. Levantamentos realizados junto a esse setor indicam, por excmplo, que as agências de viagem movimentaram no Brasil (em $1(\%) 1$ ) mais de US $\$ 2$ bilhōes em vendas de passagens aéreas nacionais c internacionais. Somando-se a isso os recursos movimentados com hospedagem, alimentaçáo e locaçāo de veículos, entre outros itens, a indústria do turismo faz girar internamente uma cifra superior a US $\$ 3$ bilhies.2

Como se vê, o turismo é um setor de grandes possibilidades, mesmo em se considerando as dificuldades atuais impostas pela política econômica recessiva do governo federal. Mas levantamentos realizados na Europa e Estados Unidos, colocam, por exemplo, que se "o turismo fosse um país" teria certamente o quarto PIB do mundo, suplantado apenas pelos produtos internos brutos dos Estados Unidos, (.EI c Japáo.

\subsection{Um Mercado de Parceria}

No momento em que se at ravessa um grave processo recessivo, cujo principal efeito é a diminuiçāo considerável do volume de negócios em praticamente todos os setores produtivos e de scrviços no País, os cartōes de crédito colocam, à disposiçāo do setor turístico, crédito ce estímulo para consumir.

A rede hotcleira nacional, que exibia uma laxa média de ocupação mensal de seus aposentos em torno de $65 \%$ atć há pouco tempo, vem registrando uma freqüência média entre $20 \%$ e $25 \%$ ao mês 3 , o que tem obrigado o setor a oferecer descontos significativos nos preços de suas diárias.

Em contrapartida, segundo levantamentos independentes realizado pelo setor, a utilizaçāo do cartāo de crédito cm restaurantes, hotéis e outros prestadores de serviços, principalmente naqueles voltados para públicos de maior poder aquisitivo, responde, respectivamente, por $45 \%$ a $70 \%$ do movimento global dessas empresas, garantindo, assim, a continuidade dos seus negócios.

Além desse vasto mercad () em potencial, o setor turístico tem ainda a mesma segurança nos recebimentos proporcionada pelo pagamento cm

2 Dados da ABECS - Associação Bräsileira de Empresas de Cartōes de Serviço.

3 Dados da ABRESI - Associação Brasileira de Hotéis. Restaurantcs. Bares e Similares. 
dinheiro. Some-se a isso a tecnologia de ponta que coloca à disposição dos clientes, tanto prestadores de cartóes como estabelecimentos.

Todo empreendedor sabe o quanto é verdadeiro o ditado que diz: "as crises, sejam elas quais forem, trazem muitos ensinamentos". Hoje, mais do que nunca, está-se aprendendo que em dias de mercados refluentes, queda do poder aquisitivo e esfriamento da economia como um tıdo, quem deseja crescer precisa de parceiros sólidos e confiáveis.

Mas se tal máxima é válida no momento, muito mais importância terá no futuro, quando o País iniciar o processo de retomada do crescimento.

O setor de turismo, onde impera uma consciência moderna e dinâmica, sabe há muito tempo que o cartão de crédito não pode ser encarado como um "mal necessário". Em vez disto, precisa ser visto como um produto de primeira linha que, em qualquer época, viabiliıa negócios que de outra forma nāo se realizariam.

Já não foi sem tempo que, em 1989, o governo brasileiro autorizou a emissão de cartōes de crédito para uso internacional, tirando os consumidores brasileiros de um "apartheid" que cobria o País de constrangimento.

A comodidade que o cartão de crédito proporciona ao turista não encontra paralelo em nenhum outro meio de pagamento. Para os que viajam, os cartōes administrados pelas empresas que operam no Brasil oferecem uma ampla relação de serviços como:

a) seguro-viagem;

b) seguro bagagem;

c) assistência médico-hospitalar e jurídica emergencial;

d) cobertura gratuita e automática para os portadores de cartōes internacionais.

Para a indústria turística brasileira, que acredita, com razão, que o número de turistas estrangeiros em visita ao Brasil pode crescer de um milhão para algo em torno de 30 milhōes ao ano, ampliar a quantidade de estabelecimentos filiados a empresas administradoras de cartōes de crédito é de vital importância.

\subsection{Atuação da Credicard}

Números recentes revelaın que cerca de $25 \%$, em média, das despesas pagas com cartōes de crédito no Brasil destinam-se à indústria turística. No caso do cartão Diners Club International, que atende um segmento com maior poder aquisitivo, cerca de $40 \%$ das despesas efetua. das através desse instrumento de crédito sào voltadas para o turismo, incluindo-se aí pagamentos a companhias aéreas, hotéis, restaurantes e bares, entre outros estabelecimentos.

A Credicard, empresa de que administra os cartocs Credicard MartesCard e Diners (lub International, possui atualmente quatro milhōes de usuários espalhados por todo o País. Hoje, investe na ocupaçáa de novos espaços no segmento turístico e, até o final de 1993, estará investindo US\$ 1,5 milhào, com o objetivi) de ampliar sua atuaçào.

Em 1992, entre as várias açōes programadas da Credicard para a área de turismo, destacam-se:

a) patrocínio de congressos, seminários e eventos;

b) comprovante de venda em dólar, para possibilitar a venda, via cartòes de crédito, de pacotes turísticos internacionais;

c) lançamento de seguro de viagens destinado aos associados dos cartōes, que poderá ser comercializado pelos agentes de viagens no momento da venda da passagem ou do pacote turístico.

O programa de parceria prevê o lançamento de novos cartōes envolvendo marcas de empresas que atuam no mercado turístico, expandindo dessa forma o projeto iniciado em agosto passado, com a colocação no mercado do cartāo Credicard-MasterCard Businesscard Bel Air4. A exemplo do que ocorre no sistema financeiro, onde possui 51 bancos associados e cartóes "co-brand"5 com cada uma dessas instituiçócs, a idéia é ampliar o número de parceiros no segmento turístico, vendendo cartōes em conjunto e distribuindo os ganhos resultantes dessas operaçōes.

Está-se realizando uma campanha dirigida aos agentes de viagem de todo o País, oferecendo prémios aos profissionais que apresentarem os maiores índices de crescimento percentual de vendas Credicard MarterCard e Diners Club International.

$\mathrm{O}$ associado tem, à sua disposição, seguro de viagem comercialirado pela rede de agências espalhadas pelo País. Ao mesmo tempo, desenvolvem-se programas de marketing com as principais companhias aćreas e operadoras internacionais de turismo.

\footnotetext{
4 Credicard - MasterCard Businesscard Bel Air: cartāo "co-brand". envolvendo a Credicard e a Bel Air - Agéncia de Viagens e Turismo.
}

5 "Co-brand": cartōes com marcas ccınjuntas. 
A parceria com o selor turístico prevé, aind at a implantaçăa de programas de treinamento do "trade", em todos os Estados da Fe deração, em conjunto com as entidades do setor, os hotckiros, os agentes de viagens, os organizadores de feiras e congressos, as locadoras de veículos etc. Da mesma forma, está-se lançando um novo programa de incentivo) ampliado e envolvendo um grande número de hotéis, operadoras internacionais, lojas de companhias aćreas etc.

A Credicard mantém, desde 1987, um acordo operacinal com a MasterCard, uma das maiores émpresas de cartóes de crédito do mundo, com 180 milhóes de usuários filiados e forte atuação nos Estados Unidos c Europa, onde o uso de cartōes de crédito integra o cotidiano das pessoas. Esse imenso contingente de turistas em potencial certamente espera encontrar em nosso País uma rede de estabelecimentos que possa atendê-lo com o mesmo nível de eficiência e rapide\% que encontra em seu país de origem.

(Os empresários do setor turístico que estiverem interessados $\mathrm{cm}$ atrair um número crescente de hóspedes estrangeiros nāo podem ignorar essas facilidades, das quais os turistas certamente nāo vão "abrir māo".

\section{CONSIDERAÇÕES FINAIS}

() fato, afinal, é que os cartōes de crédito se transformaram em algo tão familiar ao cidadão do munı lo da segunda metade do século XX, que dificilmente se imagina como seria o mundo sem cle.

Hoje, a indústria do cartão de crédito se consolidou como uma rede internacional tentacular, exercendo influência decisiva na exportaçào de serviços e produtos, nas relaçōes comerciais entre governos, na cooperação entre bancos e na competição econômica internacional. ()s quase quatro bilhōes de dólares que circulam em todo o mundo sob a forma de cartōes de crédito e serviços afins são a demonstração mais definitiva de sua transformação em parte integrante da vida diária de todos.

\section{REFERÊECLA BIBLIOGRÁFICA}

MANDELL, Lewis. 1990. The credit card industn' - A history. Boston: Twayne Publishers. $176 \mathrm{p}$. 